\title{
Klippel trenaunay syndrome-an obstetric challenge
}

\author{
Kanmani K., Meena M., Narmadha D., Geethu V. A.*
}

Department of Obstetrics and Gynecology, Government Kasturba Gandhi Hospital for Women and Children, Madras Medical College, Chennai, Tamil Nadu, India

Received: 18 February 2021

Accepted: 01 April 2021

\section{*Correspondence:}

Dr. Geethu V. A.,

E-mail: geethuva1994@gmail.com

Copyright: $(\subset)$ the author(s), publisher and licensee Medip Academy. This is an open-access article distributed under the terms of the Creative Commons Attribution Non-Commercial License, which permits unrestricted non-commercial use, distribution, and reproduction in any medium, provided the original work is properly cited.

\begin{abstract}
Klippel Trenaunay Syndrome is a rare congenital disease characterized by triad of extensive cutaneous haemangiomas (most common), venous varicosities and hypertrophy affecting a leg and/or arm on one side. We report two cases of pregnant women with Klippel Trenaunay syndrome of which one patient presented with Kasabach Merritt Syndrome (refractory coagulopathy). 24-year-old primigravida of 29 weeks with KTS presented with bleeding gums for two days. Known case of diabetes, hypothyroid on treatment and treated TB lymphadenopathy. She had hypertrophy with varicosities and haemangiomas on left lower limb and vulvar region. She was treated for thrombocytopenia at 19 weeks gestation with steroids. Laboratory studies revealed thrombocytopenia. Steroids were given as per haematologist opinion for thrombocytopenia. She had emergency caesarean section with platelet transfusion at 35 weeks as per vascular surgeon opinion. Postoperatively she was given anticoagulants and steroids. 28-year-old primigravida of 39 weeks with KTS admitted for safe confinement. She had surgery for haemorrhoids at 14 years of age and had bleeding per rectum two years back. She had hypertrophy of left lower limb and cutaneous nevus in multiple dermatomes on left half of body. Doppler left lower limb shows superficial varicosities. Laboratory studies revealed normal. With multidisciplinary approach, she had elective caesarean in view of primigravida/breech-footling presentation. Post operatively she was given anticoagulants. The success in the management of these patients requires the participation of multidisciplinary approach. The use of prophylactic anticoagulant is generally advised during the pregnancy and postpartum period.
\end{abstract}

Keywords: Klippel trenaunay syndrome, Haemangiomas, Venous varicosities, Anticoagulant

\section{INTRODUCTION}

Klippel Trenaunay Syndrome (KTS) is a rare congenital disease characterized by a triad of extensive cutaneous haemangiomas, venous varicosities and soft tissue or bone hypertrophy affecting a leg and/or arm on one side. ${ }^{1}$ The aetiology of KTS is most likely the result of a somatic mosaicism: a postzygotic mutation that only affect a subset of the cells within the body. ${ }^{2}$ Hence KTS is generally considered to be a non-hereditary disease. The complications are mostly due to vascular abnormalities that results in venous insufficiency, thrombophlebitis, cellulitis, limb disparity and thromboembolic disease. Vascular malformations arise as a result of erroneous vascular development which may be present as capillary malformations (port wine stains), venous malformations, lymphatic malformations and arteriovenous malformations. The disturbed growth in KTS includes limb hypertrophy. Both the disturbed growth and vascular malformation affect the extremities but vascular malformations can involve larger area of the body and extend to the trunk and pelvic regions. ${ }^{2}$ Pregnancy in these patients can exacerbate the complication such as postpartum haemorrhage (vascular anomalies in pelvic area) and thromboembolism (low flow state combined with physiologic prothrombotic changes). ${ }^{3}$ Most commonly seen in association with haemangiomas, Kasabach Merritt Syndrome is defined by the presence of 
thrombocytopenia and a consumptive coagulopathy. Since KTS is a rare disease, there are very few cases reported in literature regarding pregnancy outcome in women with KTS. Here we report successful management of two pregnant women with KTS of which one patient presented with Kasabach Merritt syndrome (refractory coagulopathy).

\section{CASE REPORT}

\section{Case 1}

A 24-year-old primigravida presented at 29 weeks of gestation with complaints of bleeding gums for two days. She was diagnosed as congenital venous malformation/ KTS left lower limb at the age of 5 years while being evaluated for limb swelling and MRI angiography showed multiple venous hemangiomas. No further details on her childhood therapy could be found. She had never suffered any thrombosis. During this pregnancy, she had a regular obstetrics management at her first trimester at a nearby primary health center. There was a history of excision biopsy done for left cervical lymphadenopathy in 2015 and completed ATT for TB lymphadenitis. She is a known case of hypothyroid for 18 months and on T. Thyroxine $75 \mathrm{mcg}$ and overt diabetes mellitus since 3 months of amenorrhea on injection of human insulin (R26N16/R20/R18N14) and on oral hypoglycemic agents. Patient was admitted in Stanley medical college on 16 weeks of gestation for evaluation of thrombocytopenia (platelet count 6000 cells/cu.mm) and was managed with steroids and 4 units of platelet transfusion. The local obstetrician now referred this patient to our hospital for bleeding gums and further evaluation. On examination, patient was conscious, no pallor and pedal edema. On per abdomen examination, uterus corresponds to 30 weeks, relaxed, Fetal heart rate was normal. Physical examination showed swelling, prominent hypertrophy and multiple venous varicosities of left lower limb and vulvar varicosities (Figure 1).

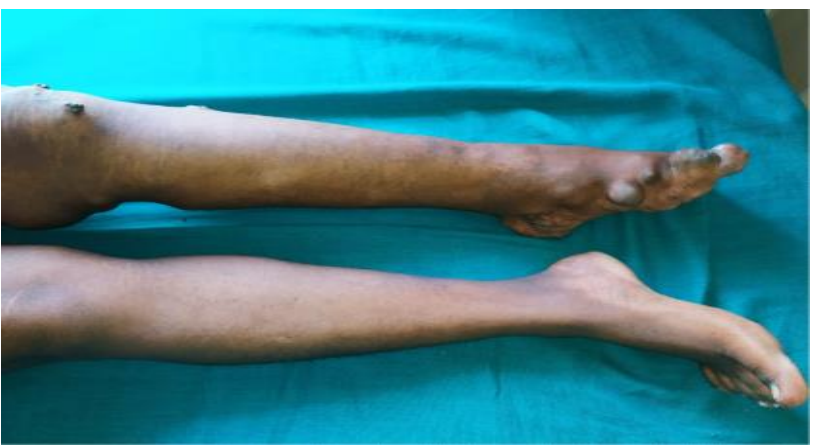

Figure 1: Multiple haemangiomas and varicosities of left lower limb.

Laboratory studies revealed normal hemoglobin (11.5 $\mathrm{g} / \mathrm{dl})$, normal total count but low platelet count (5000 cells/cu.mm) and bleeding time more than 15 mins. Rheumatological evaluation was done and found to be negative. Direct coombs test was negative. Hematology opinion obtained and advised to continue T. Prednisolone $20 \mathrm{mg}$ once a day. Doppler study of lower limb shows varicosity of left lower limb superficial and deep veins, no evidence of deep vein thrombosis and multiple hemangiomas noted in left iliac, left lower limb and left perineal regions. A multidisciplinary consulting was made with hematologist, anesthetist and vascular surgeon for evaluating the risk of pregnancy and delivery. Vascular surgeon advised for elective caesarian section for delivery in view of vulvar lesion.

At 35 weeks after steroids completion for lung maturation, she was taken for emergency caesarian section in view of fetal alarm signal with uncontrolled sugar with transfusion of 2 units of single donor platelet preoperatively and 2 units of single donor platelet postoperatively and delivered $2 \mathrm{~kg}$ baby and no abnormal findings of neonatal KTS. She was treated postoperatively with steroids and low molecular weight heparin as per vascular surgery opinion for prevention of thrombosis. Platelet count performed 5 days after delivery and it was 90000 cells/cu.mm. Bleeding time was normal. She was discharged on postoperative day 20 after hematological and rheumatological evaluation.

\section{Case 2}

28-year-old primigravida of 39 weeks gestational age admitted in our hospital for safe confinement. She was diagnosed of KTS at the age of 3 years. She suffered from hypertrophy of left lower limb $3 \mathrm{~cm}$ longer than right with few superficial varicosities of left lower limb on doppler and cutaneous nevus in multiple dermatomes on the left leg, abdomen, thorax and neck. There was no history of thrombosis. Patient underwent surgery for haemorrhoids at the age of 14 years. Patient had complaints of bleeding per rectum 2 years back, developed severe anaemia $(\mathrm{Hb} 4.2$ $\mathrm{g} / \mathrm{dl}$ ) and treated with blood transfusions. Laparoscopic ovarian cystectomy was done in 2018. She did all her regular visits in nearby primary health centre. During pregnancy, no anticoagulant was given. The patient did not demonstrate any changes in her lower limb. She was systematically examined during her hospital stay. Physical examination showed prominent hypertrophy of left lower limb (Figure 3) and cutaneous nevus in multiple dermatomes of body (Figure 2). Blood investigations were found to be normal.

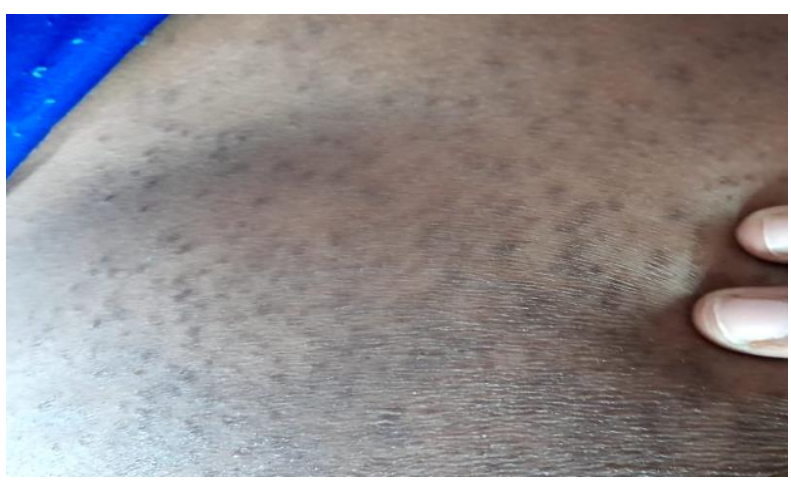

Figure 2: Cutaneous nevus on abdomen. 


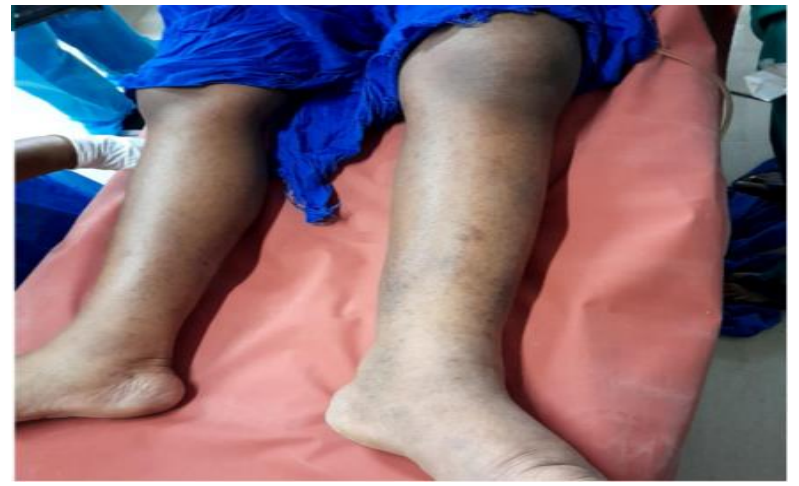

Figure 3: Hypertrophy of left lower limb.

Patient was taken for elective caesarean section in view of primi/breech with footling presentation under general anaesthesia (Figure 4). She delivered term, girl baby of weight $2.3 \mathrm{~kg}$. No blood transfusion required during hospitalization. Anticoagulants were given postnatally. Patient was discharged on postoperative day 12 .

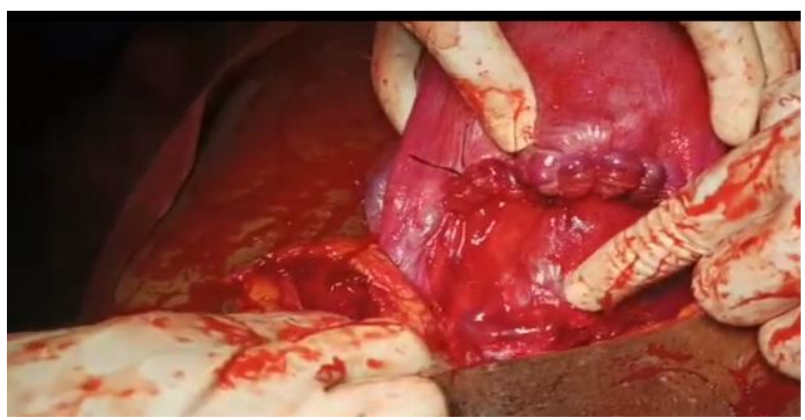

Figure 4: Intra op finding of uterine varicosity.

\section{DISCUSSION}

KTS is a rare congenital disorder of unknown origin and variable expression affecting one or more extremities and characterized by cutaneous haemangiomas and abnormal venous vessels. Physiological changes in pregnancy including increase in circulating blood volume, weight, limb oedema, changes in hormone levels, and venous obstruction by enlarged uterus worsen the capillary malformation and venous congestion present in this syndrome.

In our first case patient presented with complication of Kasabach Merritt syndrome with extensive haemangiomas. We managed the patient with multidisciplinary approach and steroids and anticoagulants. In our second case, patient presented as an asymptomatic KTS.

Tanaka et al presented a case report of KTS in which patient presented at 28 weeks of gestation with massive vulvovaginal varicosities. Systematic MRAs revealed haemangiomas and varicosities in right leg, the lower abdomen and the pubic region. Baby was delivered by caesarean section without any complications and vulvovaginal varicosities shrink postoperatively. ${ }^{1}$

Horbach et al did cross sectional study to evaluate the complications of Pregnancy with KTS. Patients with KTS were invited to participate in a comprehensive online survey about their obstetric history. Sixty women completed the survey. A total of 97 pregnancies and 86 deliveries reported in 43 patients. DVT was present in $5.8 \%$ and pulmonary embolism in $2.3 \%$ of pregnancies. Severe PPH occurred in $11 \%$ of pregnancies, compared with $5.8 \%$ in the reference population. ${ }^{2}$

Andrei et al presented a case report of 3 successfully managed pregnant women with KTS. One of the patients was diagnosed with pulmonary embolism during her pregnancy. Two of these women were identified by prothrombin gene mutation carrier. $\mathrm{He}$ advised the importance of screening for hereditary and acquired thrombophilias and magnetic resonance imaging of maternal spine and brain to identify subclinical vascular malformations. $^{3}$

Gundogan et al presented a case report of KTS in which he presented two pregnant women with syndrome. He managed first case with starting of anticoagulant antenatal and continued throughout the pregnancy. In second case, anticoagulation was started only after delivery. Despite this, she developed thrombosis. There are no prospective studies demonstrating the use of anticoagulant during pregnancy in this rare disorder. ${ }^{4}$

Neubert et al presented a case of Kasabach Merritt coagulopathy complicating KTS in pregnancy. He described a case with multiple extensive hemangiomas. Multiple hemangiomas in the right lower quadrant of the abdomen necessitated the use of a left paramedian cutaneous incision. The patient subsequently developed Kasabach Merritt Syndrome and required the transfusion of blood products as well as heparin and aminocaproic acid therapy for her postoperative management. ${ }^{5}$

Though there was no proven study validating the use of anticoagulant in the management of these patients, all these studies used anticoagulants for the betterment of the patient with better outcome. All these studies were in support of the management of our two rare cases of KTS and we had a good obstetric outcome.

\section{CONCLUSION}

KTS in pregnancy is rare. The potential for a refractory coagulopathy presenting as Kasabach Merritt Syndrome should be considered in patient with extensive hemangiomas. The success in the management of these patients requires the participation of multidisciplinary approach. The use of prophylactic anticoagulant is generally advised during the pregnancy and postpartum period to prevent thrombosis. 
Funding: No funding sources

Conflict of interest: None declared

Ethical approval: Not required

\section{REFERENCES}

1. Tanaka R, Fujita Y, Ishibashi Hiasa K, Yumoto Y, Hidaka N, et al. Successful Management of Pregnancy Complicated by Klippel-Trenaunay Syndrome Using MR Angiography-Based Evaluation. Case Rep Obstet Gynecol. 2011;2011:723467.

2. Horbach SE, Lokhorst MM, Oduber CE, Middeldorp $\mathrm{S}$, van der Post JA, van der Horst CM. Complications of pregnancy and labour in women with KlippelTrénaunay syndrome: a nationwide cross-sectional study. British J Obstet Gynecol. 2017;124(11):17808.
3. Rebarber A, Roman AS, Roshan D, Blei F. Obstetric management of Klippel-Trenaunay syndrome. Obstet Gynecol. 2004 Nov;104(5 Pt 2):1205-8.

4. Güngor Gündoğan T, Jacquemyn Y. Klippeltrenaunay syndrome and pregnancy. Obstet Gynecol Int. 2010;2010:706850.

5. Neubert AG, Golden MA, Rose NC. KasabachMerritt coagulopathy complicating KlippelTrenaunay-Weber syndrome in pregnancy. Obstet Gynecol. 1995;85(5 Pt 2):831-3.

Cite this article as: Kanmani $\mathrm{K}$, Meena $\mathrm{M}$, Narmadha D, Geethu VA. Klippel trenaunay syndrome-an obstetric challenge. Int J Reprod Contracept Obstet Gynecol 2021;10:2081-4. 